\title{
Factors Affecting Diffusion and Adoption of Agricultural Innovations among Farmers in Ethiopia Case Study of Ormia Regional State Westsern Shewa
}

\author{
Ayalew A. Worku* \\ Ethiopian Institute of Agricultural Research (EIAR), HARC, P.O.Box 2003, Addis Ababa, Ethiopia \\ *Corresponding Author: Ayalew A. Worku, Ethiopian Institute of Agricultural Research (EIAR), HARC, \\ P.O.Box 2003, Addis Ababa, Ethiopia
}

\begin{abstract}
The contribution of new technology to economic growth can only be realized when and if the new technology is widely diffused and used. Diffusion itself results from a series of individual decisions to begin using the new technology, decisions which are often the result of a comparison of the uncertain benefits of the new invention with the uncertain costs of adopting it. An understanding of the factors affecting this choice is essential both for economists studying the determinants of growth and for the generators and disseminators of such technologies. The study was to determine the factors affecting farmer's adoption of improved agricultural innovation in Welmera district western part of Oromia regional state Ethiopia. Non replaceable lottery method and proportional to size sampling techniques were employed for the selection of 130 respondents; structural questionnaires and group discussion were used. Data were analyzed using Statistical tests like chi-square, t-test, one way ANOVA and econometric model Tobit was used to identify the effect of the hypothesized variables on the dependent variable. The result of the econometric model indicated that educational level of respondent, total land holding, accesses to research and access to extension were found significant to influence adoption of improved potato production packages. The mean average age of sample respondent was 45-54. The independent t-test result shows that there was no significant difference between adopter categories in terms of age to the adoption of improved potato technology $(t=1.747, p$ 0.991). From the sample household heads $13.85 \%$ of respondent farmers are illiterate and the remaining $86.15 \%$ are educated. Majority of high adopters have been educated from grade 5 to 10 Chi-square test also shows the significant difference between adopter categories of improved potato technologies $(\chi 2=17.25 a, P=0.004)$. It is time to look participatory extension approach which invites different stakeholders. FRG approach contributed significant role in the diffusion and adoption of agricultural innovations.
\end{abstract}

Keywords: Agricultural new technology, adoption, Farmers Research Group

\section{INTRODUCTION}

The history and economics of diffusion and adoption of agricultural technologies began with the pioneering study of Griliches (1957). The process and models of adoption have been studied by different scholars, with the most popular and widely used being that of Everett Rogers, titled diffusion of innovations (Sherry \& Gibson 2002), which spans the disciplines of economics, technology, education, political science, public health, history, and communications (Dooley 1999).In literature technology and innovation are sometimes used interchangeably. While the process by which a new technology or innovation is transmitted through certain media over time to members of society is referred to as diffusion, the rate at which a new or emerging technology is adopted depends on some important attributes of the technology including the perceived advantages relative to existing ones and its compatibility with existing needs and values of the society or potential adopter, simplicity (ease of understanding and use), trial ability for potential adjustment, and observability (ease of visualizing the results) (Rogers, 2003). The adoption of improved agricultural technologies continues to be seen as an important route out of poverty in most of the developing world. Yet, as expressed by Bandier \& Rasul (2006) agricultural innovations are often adopted slowly and several aspects of adoption remain poorly understood. These are considered as potential explanations for low adoption of improved agricultural technologies. Agriculture is the supplier of basic human need, nutrition is the world's largest user of land, occupying more than one third of Earth's terrestrial surface and using vast amounts of water. It affects our daily life in many ways, both directly and indirectly. Humans expect 
agriculture to supply sufficient nutrients, economically and culturally valued foods, fibers and other products. Agriculture is essential for inclusive development because it produces food as well as economic wealth for many of the world's poorest people that allows for improved livelihoods through better health care, education, infrastructure improvements and greater investment in environmentally sound practices. For Sub Saharan Africa, growth generated by agriculture is eleven times more effective in reducing poverty than GDP growth in any other sectors (IFAD, 2013)

Despite the improvements made over the last four decades in the agricultural sector, a combination of declining soil fertility, population growth, low uptake of external inputs, and climate disruption has resulted in a dramatic fall in per capita food production (Pretty et al., 2011). In addition, the new agricultural technologies are hardly successful in Sub-Saharan Africa, where hunger is on the increase. Important pockets of poverty remain in areas characterized by rain fed agriculture or fragile soils and which affects close to one billion people. Similarly, the agricultural sector is the principal engine of growth of the Ethiopian economy employs $83 \%$ of the labor force, contributes about $90 \%$ of exports and $45 \%$ of gross domestic product (GDP), and provides about $70 \%$ of the country's raw material requirement for large-and medium scale industries (Deressa, 2009). To increase the production level of agriculture sector, we need to enhance the adoption of new technologies. However, in Ethiopia the practice is still limited due to different factors. Different studies have been conducted on adoption of agricultural technologies in Ethiopia. Furthermore, a number of scholars and policy makers strongly understood the fact that Ethiopia is, and will remain for a long time to come, a predominantly agricultural nation and maintained that agriculture is the one area from which the country can reasonably expect significant economic development in the foreseeable.

Therefore, the development of the agricultural sector largely determines the pace of economic development of the nation. Low level of technological dissemination, adoption changes, and traditional management practices are among the factors that tie smallholders to low productivity. According to Habtemariam (2004), the extension system in Ethiopia has a relatively longer history than many Sub-Saharan African countries.

Conceptual framework of the study: The conceptual framework of this study was developed to show the key components and interaction among the different stakeholders in client oriented improved potato technology adoption. In addition it tries to show effect of explanatory variables on the intensity of use of improved potato technology package. It is developed based on reviews

of theories and structural arrangements of responsible institutions to promote participatory improved potato technology development and adoption. The independent variables include: personal and demographic, economic, and institutional variables. The first frameworks showed that different stakeholder's linkages in technology development and adoption process the other frameworks showed that different factors supposed to be affects farmers decision making to adopt improved potato production packages. The two frames works to demonstrate the relationships of explanatory variables with the dependent variables rather than relationship among themselves.

\section{LITERATURE REVIEW}

\subsection{Definitions and Concepts}

Adoption: According to Feder et al. (1985) adoption may be defined as the integration of an innovation into farmers' normal farming activities over an extended period. Adoption, however, is not a permanent behavior. Dasgupta (1989) noted that an individual may decide to discontinue the use of an innovation for a variety of personal, institutional, and social reasons one of which might be the availability of another practice that is better in satisfying farmers' needs. Feder et al. (1985) classified adoption as an individual (farm level) adoption and aggregate adoption. Adoption at the individual farmers' level is defined as the degree of use of new technology in long run equilibrium when the farmer has full information about the new technology and its potential in the context of aggregate adoption behavior within a region. This implies that aggregate adoption is measured by the aggregate level of specific new technology with a given geographical area or within the given population. Overall, to explain adoption behavior and factors affecting technology adoption, three paradigms are commonly used. The paradigms are: the innovation diffusion model, the adoption perception and the economic constraints models. 
The underlying assumption of the innovation-diffusion model is that the technology is technically and culturally appropriate, but the problem of adoption is one of asymmetric information and very high search cost (Feder et al., 1985). The second paradigm, the adopters' perception paradigm, on the other hand, suggests that the perceived attributes of the technology condition adoption behavior of farmers. This means that, even with full farm household information, farmers may subjectively evaluate the technology differently than scientists (Kivlin \& Fliegel, 1967). Thus, understanding farmers' perceptions of a given technology is crucial in the generation and diffusion of new technologies and farm household information dissemination. The economic constraint model contends that input fixity in the short run, such as access to credit, land, labor or other critical inputs limits production flexibility and conditions technology adoption decisions. Aikensetal. (1975) recent studies have shown that using the three paradigms in modeling technology adoption improves the explanatory power of the model relative to a single paradigm.

Agricultural new technologies: Agricultural new technologies constitute the introduction and use of hybrids, the greenhouse technology, genetically modified food, chemical fertilizers, insecticides, tractors and the application of other scientific knowledge (Matunhu, 2011). Agricultural new technologies are the factors of production which have undergone some form of amendment from their original state with the intent of enhancing their performance.

FRG (Farmers Research Group): is one of the participatory agricultural research approaches aimed to improve the conventional top-down research approach that doesn't fully address the needs of subsistence and small holder farmer. The concept to FRG as an extension methodology was first introduced to Latin America by local agricultural research community as a focal point for PTD (participatory technology development). Through time, the concept to FRG has spread to different Asian and African countries. When FRG was introduced to Africa, there was resistance by natural scientists who were biased in favor of applied research. At that time, different people gave different meanings to FRG. For instance, some said FRG is a group of people who does just similar activities of what researchers do in the normal job, while others said it is group of people who focus on "transfer of technology"

Factors Affecting Adoption of Agricultural New Technologies: In Ethiopia various factors influence agricultural technology adoption those factors can be grouped into three broad categories (1) Personal and demographic variables related to the characteristics of producers i.e., the farmers; (2) Socio-Economic variables related to the characteristics and relative performance of the technology and (3) Institutional variables (Teklewold et al., 2013).

The factors related to the characteristics of producers include education level, experience with the activity, age, gender, level of wealth, farm size, plot characteristics, labor availability, resource endowment, risk aversion, etc. The factors related to the characteristics and performance of the technology and practices include food and cash generation functions of the product, the perception by individuals of the characteristics, complexity and performance of the innovation, its availability and that of complementary inputs, the relative profitability of its adoption compared to substitute technologies, the period of recovery of investment, local adoption patterns of the technology, the susceptibility of the technology to environmental hazards, etc. The institutional factors include availability of credit, the availability and quality of information on the technologies, accessibility of markets for products and inputs factors, the land tenure system, and the availability of adequate infrastructure, extension support, etc. Enabling policies and programs, market linkages, access to institutional support and credit were found to play a positive role in stimulating farmer investment in and adoption of sustainable technologies (Shiferaw et al., 2009).

\section{Methodology}

Welmara is one of the weredas (Districts) in the Oromia Region of Ethiopia. It is part of the Oromia Special Zone Surrounding Addis Ababa, which is bordered in the south by the Sebeta Hawas, on the west by Mirab Shewa Zone, on the North by Mulo, in the North East by the Sululta, and in the East by Addis Ababa. The highest point in this wereda is mount Wechacha 3191 meters above sea level (m.a.s.l) it is s located in West Shewa Zone about $21 \mathrm{~km}$ West of Addis Ababa, it is situated between $08^{\circ} 50^{\prime} 04^{\prime \prime} \mathrm{N}$ to $09^{\circ} 12^{\prime} 55^{\prime \prime} \mathrm{N}$ latitudes and $42^{\circ} 55^{\prime} 32^{\prime \prime} \mathrm{E}$ to 430 o $14^{\prime} 19^{\prime \prime} \mathrm{E}$ longitudes and at altitude of 2390 masl. The area has a bimodal rainfall pattern, receiving an annual rainfall more than $1060 \mathrm{~mm}$. 
The short rains extent from March to April, and the long rains from July to October. The two Study sites Ilala Gojo and Telecho in Welmera district located at 43o02' 02"E to 43o05' 38"E longitudes and 09 o $02^{\prime} 34^{\prime \prime} \mathrm{N}$ to 09 o $06^{\prime} 46 " \mathrm{~N}$ latitude Farmers in the area are engaged in vegetable, crop livestock mixed agriculture.

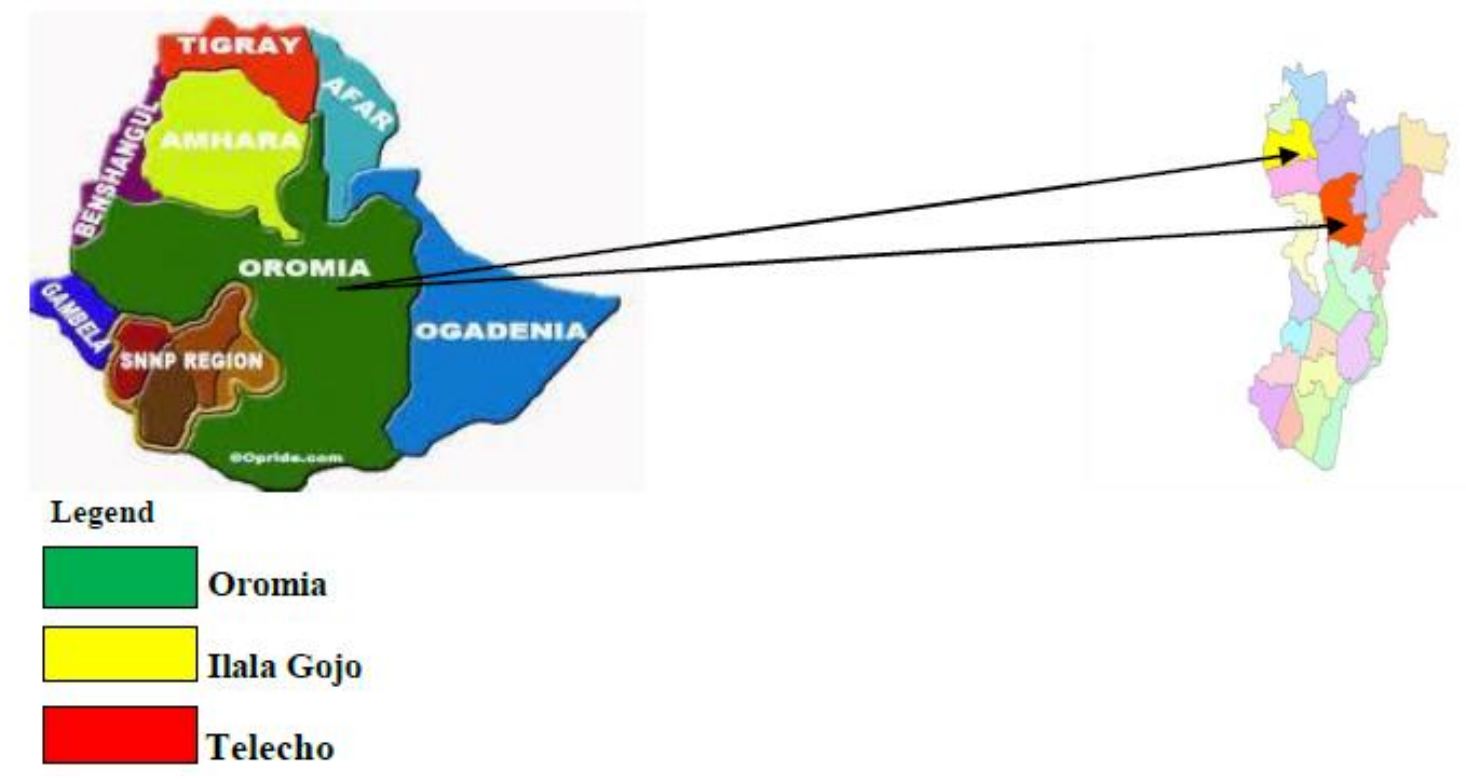

Figure1. Study site map

Source: Welmera districtAgriculture office. Year 2015

Multi-stage sampling methods were employed. As a First step, one district and two sub district (Telecho and IlalaGojo) were selected purposefully because of the presence of different FRGs operating in the district. Then from the two k district, a total of 217 potato growers were registered in the cropping season 2013. Among the registered farmers 150 were from Telecho sub district and the remaining 67 from Ilala Gojo sub district From Telecho sub district 88 farmers were Non-FRG participants and 62 farmers belonged to name of Woleda Gudeni potato producer participants and 30 belonged to name of Didimtu Burka Misoma potato producer FRG. Using non replaceable lottery method and proportional to size sampling techniques 54 FRG members and 76 non participant member farmers which, totally 130 samples were selected.

Primary data and analysis: Using structured interview schedule, both qualitative and quantitative primary data were gathered from FRG participant farmers and nonparticipant farmers. Interview schedule and group discussions have been conducted to gather information of demographic characteristics, socioeconomic, institutional dimensions to find out the determinant factors of adoption of improved potato production package.

Definition of variables and hypotheses: Dependent variable, Adoption Index (AI) is the dependent variable for this study. It indicates the extent of adoption of improved potato technology packages. It is a type of constrained continues dependent variable. But this study examined the Independent variables factors which influences the extent of adoption of improved potato production packages.

Education: Measured in terms of number of years of formal schooling the respondents had completed atthe time of data collection. It was assumed that a better educated farmer can understand the information very easily and internalize the information transferred from development agents, researchers, NGOs and other development stakeholders. It is a dummy variable 1 was given for who can read and write farmers and, 0 for otherwise. Education in this study is measured as continuous variable ranging from illiterate to read and write respondents. Many study reported that education showed positive and significant relationship with adoption (Nkonya et al. 1997; Bekele et al. 2000). Therefore, in this study it is hypothesized to affect level of use of potato technology package positively.

Age: In rural traditional societies, age serves as an important indicator of the individual's position in the society. Older farmers will be in a position to experience much with their traditional farming 
practices and are expected to be less responsive to participate in group works and accept newly introduced agricultural technologies. In addition, they are usually risk averters particularly in crops such as potato production because of high risks of product perish ability and price fluctuation and they tend to be reluctant to fully adopt the package. Million and Belay (2004) showed age has negative and significant influence on the adoption of fertilizers. Moreover, Mulugeta (1994) on his study on smallholder wheat technology adoption in South Eastern highlands of Ethiopia reported that age had a negative effect on the adoption of wheat technologies. Therefore, in this study it is hypothesized that age is negatively correlated with intensity of use of potato technologies Land is an important resource for agricultural production. The same true for potatoes production the farmers who have large land size could show the capability of an individual farmer to adopt new improved potato technologies. Land is measured by hectare. It was assumed that the larger the farm size the farmer has, the better his risk bearing ability and the higher the probability to adopt improved technologies. Different studies reported its effect differently. For example, a study by Mulugeta, (2000), Million and Belay (2004), Mwangae et al. (1998) and Yishak (2005) indicated positive relationship between farm size and adoption. Similarly Tesfaye et al. (2001) reported that farm size contributed positively in farmers' adoption of improved wheat varieties. In this study the size of irrigable land expected to positively affect extent of use of technology.

Livestock ownership: Livestock are also an important income sources which enables farmers to invest on adoption of improved agricultural technologies. No doubt that in most cases, livestock holding has positive contribution to household's adoption of agricultural technologies many adoptions Studies have reported positive effect of livestock holding on adoption .It is the number of livestock the farmer owned. Livestock is so many things for farmers for instance traction power, manure and source of income by selling the animals and by product. It was assumed that livestock affects the adoption of improved potato technologies. A study conducted by Bekele et adopters Therefore, livestock-holding number assumed affects adoption and extent technologies package positively al., (2000) added that adopters of improved wheat technologies owned more livestock than non

Accesses to extension and agricultural research: This refers to farmer's access to information on agricultural technologies through participation in training, workshop, and field day/visit and on-farm demonstration arranged by extension organizations. It refers to the number of times the farmer had participated in the three extension events i.e. training; field days and demonstration in the last three years many studies conducted so far have indicated that participation in such arrangements would have positive influence on adoption of agricultural technologies. It is a dummy variable (1 was given for who have extension contact and 0 for others).

It refers to farmers access to research Thus, having access to research centers was expected to influence adoption of potato production package positively. It is a dummy variable, which takes the value ( 1 if the farm household has accesses to research and 0 , otherwise). Number of studies reveled positive relationship of accesses to research with adoption. Among these Getahune (2000) and Legesse (1992) some of them therefore, accesses to research were hypothesized that affect adoption and extent of technology package positively.

\section{RESUltS AND DiSCUSSION}

Extent of adoption of improved potato production package: In order to know the level of adoption of each respondent the Adoption Index score was calculated. Before the calculation the technology packages were listed and weighted. Equal weights were given to all technology packages considered through discussion with researchers and extension workers in the study area. A total of four improved production packages were used .These are varieties, fertilizer application rate, chemical spraying, cultivation frequency, the sample respondents adoption index scores were categorized in to three adopter groups namely non-adopter, low and high adopter the actual adoption index score ranges from 0 to 1 . Adoption index score of 0 point implies non-adoption of the overall improved potato production package. Statistical analysis of ANOVA indicated that there was significant variation $(\mathrm{F}=$ $34.47, \mathrm{P}=0.000$ ) among the adoption index score between the three categories at $1 \%$ level of significant which indicates difference of adoption of potato technology packages among sampled nonFRG (Table 1). As indicated in Table 1, non-adopter accounts for $65.8 \%$ with the mean adoption index of 0.0000 . This indicated that non adopter was not practicing any of the recommended package and the technologies in the production year of 2013. Next to non-adopters, low adopters constituted 
Factors Affecting Diffusion and Adoption of Agricultural Innovations among Farmers in Ethiopia Case Study of Ormia Regional State Westsern Shewa

about $28.9 \%$. They have mean adoption index of 0.4670 while high adopters constituted about $5.2 \%$ with mean adoption index were 0.0956 (Table 1).

Table1. Distribution of non-FRG member's respondents by adoption category of improved potato technologies

\begin{tabular}{|l|l|l|l|l|l|l|l|}
\hline Adoption Category & $\mathrm{N}$ & percent & Adoption index score & Mean & SD & F & P \\
\hline Non-Adopter & 50 & 65.8 & $0.00-0.000$ & 0.00000 & & & \\
\hline Low -Adopter & 22 & 28.9 & $0.01-0.30$ & 0.4670 & 0.06858 & & \\
\hline High-Adopter & 4 & 5.2 & $0.31-1$ & 0.0956 & 0.00762 & & \\
\hline Total & 76 & 100 & $0.00-1$ & 0.2212 & 0.22124 & $34.47^{* * * *}$ & 0.000 \\
\hline
\end{tabular}

$* * *=$ significant at $1 \%$ level

Table2. Distribution of FRG member's respondents by adoption category of improved Potato technologies

\begin{tabular}{|l|l|l|l|}
\hline Adoption Category & N & Percent & Adoption Index Score \\
\hline High & 54 & 100 & 1 \\
\hline Total & 54 & 100 & \\
\hline
\end{tabular}

\subsection{Determinant Factors for the Adoption of Improved Potato Technologies}

\subsubsection{Household's Personal Characteristics}

Age:-Is one of the household characteristics important to describe households and can provide a hint as to age structure of the sample respondent and has impacts in terms of technology adoption. Older farmers could be fast adopters because they have enough farming experience in the field of agriculture (Tadesse, 2008). This is not in agreement with the following sentence written by same Author. On the other hand, because of risk averting nature older farmers are more conservative than younger farmers to adopt new agricultural technologies (Tadesse, 2008).In the study the age ranges from 25 to 65 years. The mean average age of sample respondent was 46 years and the independent t-test result showed that there was no significant difference between adopter categories in terms of age to the adoption of improved potato technology $(\mathrm{t}=1.747, \mathrm{p}$ 0.991) $)$. The finding of this study is in agreement with the one conducted by Tesfaye et al., (2001) were adoption of improved wheat and inorganic fertilizer does not significantly different in terms of age between adopters and non adopters.

Table3. Age statuses of sampled respondents

\begin{tabular}{|l|l|l|l|l|l|l|}
\hline Variables & Adoption Category & $\mathrm{N}$ & Mean & SD & $\mathrm{t}$ & $\mathrm{P}=$ value \\
\hline Age & Non-adopter & 50 & 46.2 & 15.37 & & \\
\hline & Low adopter & 22 & 45 & 11.63 & & \\
\hline & High adopter & 58 & 37.5 & 11.33 & & \\
\hline & Total & 130 & 45.54 & 13.92 & $1.747 \mathrm{NS}$ & 0.991 \\
\hline
\end{tabular}

$t=1.747, P=0.991 . N S$

Education: - enhances the capacity of individuals to obtain, process, and utilize information from different sources. Farmers need enough information about the technology to make the right decision. A better educated farmer can understand the information very easily and internalize the information transferred from extension workers, agricultural researchers and other development stakeholders from the sampled households $14 \%$ of respondents farmers are illiterate and the rest education status of sampled respondents $86 \%$ are educated Majority of high adopter have been educated from grade 5 to $>10$ grade (Table 4).It helps them to internalize what agricultural experts said and applied the technology packages properly. Chi-square test also shows the significant difference between adopter categories of improved potato technologies $(\chi 2=17.25 \mathrm{a}, \mathrm{P}=0.004)$.

Table4. Education statuses of sampled respondent

\begin{tabular}{|c|c|c|c|c|c|c|c|c|c|}
\hline Adoption Categories & Illiterate & Read \& write & $1-4$ & $5-8$ & $9-10$ & $>10$ & Total & $\chi 2$ & P \\
\hline Non-adopter & 18 & 12 & 10 & 3 & 6 & 1 & 50 & & \\
\hline Low - adopter & 2 & 2 & 8 & 5 & 2 & 3 & 22 & & \\
\hline High - adopter & 3 & 6 & 9 & 16 & 10 & 14 & 58 & & \\
\hline Total & 23 & 20 & 27 & 24 & 18 & 18 & 130 & $17.257 \mathrm{a}$ & 0.004 \\
\hline
\end{tabular}

$* *(\chi 2=17.25 a, P=0.004)$.

International Journal of Research Studies in Agricultural Sciences (IJRSAS) 
Factors Affecting Diffusion and Adoption of Agricultural Innovations among Farmers in Ethiopia Case Study of Ormia Regional State Westsern Shewa

\subsubsection{Economic Factors}

Landholding: - Is perhaps the single most important resource as it is a base for any economic activities especially in rural and agricultural sector. In the study area, the maximum land size owned by sample households was 1.25 ha while the minimum was 0.25 ha. In this study, from non-FRG members large size landholder farmers are adopters of new potato technologies. The mean land holding of non-adopters, low and high adopters are 0.36, 0.66 and 1hectares respectively .Analysis of variance also shows significant difference among adoption categories $(\mathrm{t}=17.65, \mathrm{P}=0.000)($ Table 5)'

Table5. Non-FRG Land holding of sampled respondents

\begin{tabular}{|l|l|l|l|l|l|l|}
\hline Land in hectare & Adoption Categories & $\mathrm{N}$ & Mean & SD & $\mathrm{t}$ & P value \\
\hline & Non-adopter & 50 & 0.36 & .351 & & \\
\hline & Low adopter & 22 & 0.66 & .182 & & \\
\hline & High adopter & 4 & 1 & .204 & & \\
\hline Total & & 76 & .480 & .237 & $17.65^{* * *}$ & 0.000 \\
\hline
\end{tabular}

***, significant at $1 \%$ probability level

Table6. FRG members Land holding of sampled respondents

\begin{tabular}{|l|l|l|l|l|l|l|}
\hline Land in Categories hectare & Adoption & $\mathrm{N}$ & Mean & SD & $\mathrm{t}$ & P value \\
\hline Total land holding & High adopter & 54 & 0.86 & .246 & & \\
\hline & Total & 54 & 0.86 & .246 & $26.09^{* * *}$ & 0.000 \\
\hline
\end{tabular}

***, significant at $1 \%$ probability level

Livestock holding: is an indicator of household's wealth position in the rural context. Livestock production is an important component of the farming system in the study area was farmers use mixed farming systems. Livestock means so many things for farmers for instance traction power, manure and source of income by selling the animals and by- products. The average livestock ownership of the non-FRG respondent farmers was nearly 2 . The minimum and maximum livestock ownerships of the farmers were 0 and 6 TLU respectively (Table 7). Statistical test shows insignificant difference (t 6.262, $\mathrm{p}=0.293$ ) between livestock ownership and the adoption of improved potato production packages with $\mathrm{T}$ finding has similarities with Tadesse (2008).

Table7. Non-FRG Livestock ownership (TLU)

\begin{tabular}{|l|l|l|l|l|l|}
\hline Adoption Categories & $\mathrm{N}$ & Mean & SD & t & P value \\
\hline Non-adopter & 50 & 1.86 & 1.09 & & \\
\hline Low-adopter & 22 & 1.95 & 0.844 & & \\
\hline High adopter & 4 & 2.5 & 1.29 & & \\
\hline Total & 76 & 1.92 & 1.20 & $6.262 \mathrm{NS}$ & .0293 \\
\hline
\end{tabular}

$t=6.262 p=.0293 \mathrm{NS}$

Table8. FRG members FRG Livestock ownership (TLU)

\begin{tabular}{|c|c|c|c|c|c|}
\hline Adoption Categories & $\mathrm{N}$ & Mean & SD & $\mathrm{t}$ & P value \\
\hline High adopter & 54 & 3.04 & 0.776 & & \\
\hline Tota & 54 & 3.04 & 0.776 & $28.75^{* * *}$ & 0.000 \\
\hline
\end{tabular}

***, significant at $1 \%$ probability level

\subsubsection{Institutional Factors}

Access to Agricultural research Holeta Agricultural Research Center is the main source of information on new technologies for potato farmers in the study area. This center has made its services accessible to farmers mainly through formed FRGs, by arranging training, workshop, field day visit, on-farm demonstration and on-farm trial. It is hypothesized that frequent contact with agricultural researchers will increase farmer's probability of adopting improved agricultural technologies. Among Non-FRG members with adoption categories non-adopter $(100 \%$,$) low adopter (90.9 \%)$ and high adopter $(50 \%)$ of therespondents have no accesses to research. But $100 \%$ of FRG members have assesses to research and Chi-square test also shows that there is a significant difference between FRG members and nonmembers in assesses to agricultural research $(\chi 2=101.307 \mathrm{a}, \mathrm{P}=0.000)$ (Table 9). Thus increasing farmers' participation in research activities can increase participation in improved potato technology 
Factors Affecting Diffusion and Adoption of Agricultural Innovations among Farmers in Ethiopia Case Study of Ormia Regional State Westsern Shewa

package adoption and the result of this study is in agreement with the findings of many authors. For instance, Tesfaye et al. (2001), in the study on adoption of improved bread wheat varieties and inorganic fertilizer by small-scale farmers, reported that participation in on-farm demonstration and participation of training contributed positively to farmers participation and adoption.

Table9. Accesses to agricultural research

\begin{tabular}{|c|c|c|c|c|c|c|c|}
\hline Adoption Categories & No & Yes & No & Yes $\%$ & NO \% & $\chi 2$ & P=value \\
\hline Non-adopter & 50 & - & 50 & - & 100 & & \\
\hline Low adopter & 22 & 2 & 20 & 9.1 & 90.9 & & \\
\hline High adopter & 4 & 2 & 2 & 50 & 50 & & \\
\hline FRG high adopter & 54 & 54 & - & 100 & - & & \\
\hline Total & 130 & 58 & 72 & 39.77 & 60.22 & $101.31^{\mathrm{a}}$ & .000 \\
\hline
\end{tabular}

***, significant at $1 \%$ probability level

\subsubsection{Access to Extension}

In the study area the common extension events that were used as a substitution for participation in extension include demonstration, farmer's field day, and trainings. These extension activities are the major source of agricultural information that equip farmers with the necessary knowledge and skill about the new agricultural technologies and as a result farmer would be more likely to participated and adopt new improved potato technologies. Non-FRG members with adoption categories of nonadopter (90\%) and low adopter (27.78\%) have no accesses to extension. Whereas high adopter from non FRG $100 \%$ have accesses to extension but $69 \%$ of FRG members have assesses to extension which directly organized by wereda level agricultural office. Chi-square test also shows that there is a significant difference between FRG members and non-members in access to agricultural extension $(\chi 2=18.590 \mathrm{a}, \mathrm{P}=0.000)$ (Table 10). This implies that FRG member farmers and high adopters from non-FRG members participated in the extension events. This finding also agrees with Edluss (2006). Table10. Access to Extension

\begin{tabular}{|c|c|c|c|c|c|c|c|}
\hline Adoption Categories & No & Yes & No & Yes $\%$ & NO $\%$ & $\chi^{2}$ & P=value \\
\hline Non-adopter & 50 & 5 & 45 & 10 & 90 & & \\
\hline Low adopter & 22 & 16 & 6 & 72.22 & 27.78 & & \\
\hline High adopter & 4 & 4 & - & 100 & - & & \\
\hline FRG high adopter & 54 & 37 & 17 & 68.52 & 31.48 & - & \\
\hline Total & 130 & 62 & 68 & 62.98 & 37.02 & $18.590^{\mathrm{a}}$ & .000 \\
\hline
\end{tabular}

***, significant at $1 \%$ probability level

Table11. Variable Coefficient

\begin{tabular}{|c|c|c|c|c|}
\hline Variable Coefficient & Estimated & Standard error & T & P=value \\
\hline AGE & -.0013105 & .9966604 & -0.03 & 0.897 \\
\hline EDU & .185146 & .0857708 & $1.88^{* *}$ & 0.040 \\
\hline LANHO & .1023712 & .0271121 & $2.81^{* * *}$ & 0.000 \\
\hline LIVSTO & 0002305 & .0268286 & 0.01 & 0.881 \\
\hline ACESSAGRES & 3257437 & .0772683 & $3.38^{* * *}$ & 0.000 \\
\hline ACESSEXT & 2543525 & .0 .543362 & $4.12^{* * *}$ & 0.000 \\
\hline FRGM. & 292717 & 0.428348 & $3.05^{* * *}$ & 0.000 \\
\hline Constant & -215274 & 1224055 & -1.56 & 0.064 \\
\hline /sigma & .3226762 & .0316416 & & \\
\hline Log likelihood function=21.045534 & \multicolumn{4}{|l}{} \\
\hline ANOVA best fit measure $=\mathbf{0 . 4 2 4 4}$ \\
\hline P=0.000
\end{tabular}

Source: Model output, ***, *** represents $1 \%, 5 \%$ and $10 \%$ level of significant

Education: Educational level increases farmers' ability to get process and use information and increase farmers' willingness to adopt a new technology. Several studies, for example, those conducted by Itana (1985), Chilot etal. 1996), kansana(1996), Asfaw et al.(1997), Mwanga et al. (1998) and Tesfaye et al. (2001) had reported that education had positive and significant relationship with adoption. In this case education had positively and significantly influenced the adoption and extent of adoption of improved potato production package at 5\% probability level. This explanatory variable accounts $18.5 \%$ of variation on probability and extent of adoption of improved potato 
production package. On the other word, it said that it would increase by $18.5 \%$ the probability of potato technology package adoption. Therefore, it was hypothesized that education influences adoption of improved potato production technology positively. This result has similarity with Yitayal (2004) research findings.

Land holding: Total land holding had positive and significant influence on the adoption and extent of adoption of improved potato production package at $1 \%$ probability level. The explanatory variable accounts $10.2 \%$ of variation on adoption and extent of adoption of improved potato production packages. The result indicates that farmers who have larger land size are in a better position to adopt the potato package.

Accesses to research: Had positive significant influence on the adoption and extent of adoption of improved potato production package at $1 \%$ probability level. This independent variable accounts $32.5 \%$ of variation on adoption and extent of adoption of improved potato production package. On the other word farmers who have more accesses toresearch has more exposure to have information on new agricultural technologies. Similarly, on the adoption of improved potato production package adopter from FRG members' farmers have more frequent contact with agricultural researchers than non - FRG farmers.

Accesses to Extension: Many research findings across space and time agree in the positive association of accesses to extension and adoption of technologies. In a similar manner the result of the Tobit model in this study reveals that adoption of improved potato technology package by the respondent farmers were positively influenced by accesses of extension and it is statistically significant at less than $1 \%$ probability level. This independent variable accounts $25.4 \%$ of variation on adoption and extent of adoption of improved potato production packages.

FRG membership: Participant Farmers in FRG has increases farmers ability in technology adoption and dissemination and also creates favorable condition to farmers in exchanging information and participate in different agricultural training. Generally it serves as platform to the intervention and adoption of technologies. This implies that farmers participate as a member in FRG has significantly influenced the adoption and extent use of improved potato production package and it is statistically significant at less than $1 \%$ probability level. This independent variable also accounts $29.2 \%$ of variation on adoption and extent of improved potato production packages.

\section{CONCLUSION AND RECOMMENDATION}

Agricultural technology development is an essential strategy for increasing agricultural productivity, achieving food self-sufficiency, alleviating poverty and food insecurity among smallholder farmers in Ethiopia. In Ethiopia, farmers have been adopting and using different agricultural technologies, the adoption of technologies has not completely optimal yet. The variables significantly affect the adoption of agricultural new technologies by farmers are education level, land holding, accesses to agricultural research and extension service. From this study FRG (farmers research group) contributed significant role by adopting and diffusion of new agricultural technologies. Now it is time to look improved extension approach which needs participation of different stakeholders. Therefore, it needs to further promote agricultural new technologies by designing an approach based on farmer's problem and need.

\section{REFERENCES}

[1] Aikens MT, Havens AE and Flinn WL (1975). The adoption of technology: the neglected role of institutional constraints. Mimeograph, Department of Rural sociology Ohio S. University USA

[2] Bandiera, O., and I. Rasul. 2006. Social Networks and Technology Adoption in Northern Mozambique. The Economic Journal 116 (514): 869-902

[3] BekeleHundieKotu, H. Verkuijl, W. Mwuagi, and D. Tanner. 2000. Adoption of Improved Wheat Technologies in Adaba and Dodola Districts of Bale Highlands, Ethiopia. In: Mexico, D.F.: International Maize and Wheat Improvement Center (CIMMYT) and Ethiopian Agricultural Research Organization (EARO)

[4] ChilotYirga, Shapiro, B.I, and MulatDemeke, 1996. Factors influencing adoption of new wheat technologies in Wolmera and Addis Alem Areas of Ethiopia. Ethiopian Journal of Agricultural economics, 1:63-83.

[5] Dasgupta S (1989) Diffusion of Agricultural Innovations in Village India. Wiley Eastern Limited, New Delhi, p: 231. 
[6] Deressa A (2009) Achievement and Challenges in Ethiopian Agriculture. Ministry of Agriculture and Rural Development MoARD, Ethiopia.

[7] Dooley, K.E. 1999. Towards a Holistic Model for the Diffusion of Educational Technologies: An Integrative Review of Educational Innovation..

[8] Feder G, Just RE, Zilberman D (1985) Adoption of Agricultural Innovation in Developing Countries: "A Survey". Economic Development and Cultural Change 32: 255-298.

[9] Getahun, D., 2004. Assessment of Factors Affecting Adoption of Wheat Technologies and Its Impact.The Case of Hula District, Ethiopia.An M.Sc. Thesis Presented to School of Graduate Studies of Haramaya University, Ethiopia

[10] Griliches, Z. 1957. Hybrid Corn: An Exploration in the Economics of Technology Change. Econometrica 25: 501-522

[11] Habtemariam, A, 2004.The Comparative Influence of Intervening Variables in the Adoption Behavior of Maize and Dairy Farmers in Shashemene and DebreZeit, Ethiopia. PhD. Dissertation University of Pretoria. Pretoria. 292. P.

[12] IFAD (2013) African agricultural development: opportunities and challenges. Statement by IFAD President at the 6th Africa Agriculture Science Week and FARA General Assembly

[13] Kivlin JE, Fliegel FC (1967) Differential perceptions of innovations and rate of adoption. Rural Sociology 32: 78-91.

[14] Langyintuo, A.S., Mwangi, W., Dialo, A. O., Mac Robert, J., Dixon, J. \&Banziger, M. (2008). An analysis of Bottlenecks affecting the production and deployment of maize seed in eastern and southern Africa. Harare, Zimbabwe, CIMMYT

[15] Matunhu J (2011) A critique of modernization and dependency theories in Africa: Critical assessment. Afr J Hist Cult 3: 65-72.

[16] Million, T., and Belay, K., 2004. Determinants of fertilizer use in Gununo Area, Ethiopia. In agricultural technology evaluation, adoption and marketing: proceedings of the workshop held to discuss the socioeconomi c results of 1998-2002 from August 6 - 8, 2002 Ethiopian Agricultural Research Organization, Addis Ababa

[17] Mulugeta, E., 2000. Determinants of Adoption of Soil Conservation Practices in Central Highlands of Ethiopia.The Case of Selale. An M.Sc. Thesis Presented to School of Graduate Studies of Haramaya University, Ethiopia

[18] Rogers, E.M. 1983. Diffusion of Innovation. 3rd ed, 236. New York: The Free Press.. 2003. Diffusion of Innovations. 5th ed. New York: The Free Press

[19] Sherry, L., and D. Gibson. 2002. The Path to Teacher Leadership in Educational Technology.

[20] Shiferaw BA, Okello J, Reddy RV (2009) Adoption and adaptation of natural resource management innovations in smallholder agriculture: reflections on key lessons and best practices. Environment, Development and Sustainability 11: 601-619.

[21] Teklewold H, Kassie M, Shiferaw B (2013) Adoption of multiple sustainable agricultural practices in rural Ethiopia. Journal of Agricultural Economics 64: 597-623.

[22] Tesfaye ,Z., Bedassa, T, and Shiferaw, T., 2001. Adoption of high yield in maize technologies in major maize growing regions of Ethiopia. Ethiopian Agricultural Research Organization, Addis Ababa

Citation: Ayalew A. Worku, "Factors Affecting Diffusion and Adoption of Agricultural Innovations among Farmers in Ethiopia Case Study of Ormia Regional State Westsern Shewa” International Journal of Research Studies in Agricultural Sciences (IJRSAS), 2019; 5(9), pp. 27-36, http://dx.doi.org/10.20431/24546224.0509004

Copyright: () 2019 Authors. This is an open-access article distributed under the terms of the Creative Commons Attribution License, which permits unrestricted use, distribution, and reproduction in any medium, provided the original author and source are credited. 